\title{
Dielectric and electrical properties of $\mathrm{ZnSb}_{2} \mathrm{O}_{4}$ ceramics
}

\section{Anita Mekap, Piyush R. Das, R. N. P. Choudhary}

Department of Physics, Institute of Technical Education \& Research, Siksha 'O'Anusandhan University, Jagmohan Nagar, Jagamara Bhubaneswar 751030, India

*Corresponding author. Tel: (+91) 8763425977; E-mail: crnpfl@ gmail.com

Received: 06 January 2013, Revised: 22 March 2013 and Accepted: 16 April 2013

\section{ABSTRACT}

The polycrystalline sample of $\mathrm{ZnSb}_{2} \mathrm{O}_{4}$ was prepared by a high-temperature solid-state reaction technique. Preliminary X-ray diffraction (XRD) studies of powder sample of $\mathrm{ZnSb}_{2} \mathrm{O}_{4}$ showed the formation of single-phase compound at room temperature. The surface morphology of the pellet sample of $\mathrm{ZnSb}_{2} \mathrm{O}_{4}$ was recorded at room temperature using a scanning electron microscope (SEM). Detailed studies of dielectric properties $\left(\varepsilon_{\mathrm{r}}\right.$, tan $\left.\delta\right)$ and impedance parameters of the material provide an insight into the electrical properties and understanding of types of relaxation process occurred in the material. Temperature variation of $\mathrm{dc}$ conductivity shows that this compound exhibits negative temperature coefficient of resistance (NTCR) and frequency dependence of ac conductivity suggests that the material obeys Jonscher's universal power law. Copyright (C) 2014 VBRI press.

Keywords: Ceramics; XRD; electrical conductivity; impedance spectroscopy.
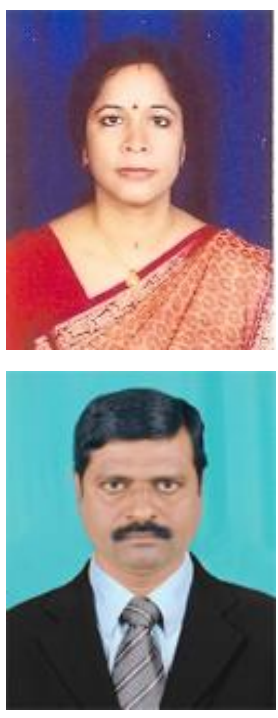

P. R. Das was born in Cuttack (Orissa) in 1963. He is a postgraduate (1987) in Physics from Ravenshaw college, Cuttack. He did his $\mathrm{PhD}$ in Physics (Condense Matter) from IIT Kharagpur in 2008. He is presently working as Associate Professor in the Department of Physics, Institute of Technical Education \& Research (Siksha O Anusandhan University), Bhubaneswar, Orissa. His major field of research is in the area of multiferroics/ferroelectric materials.

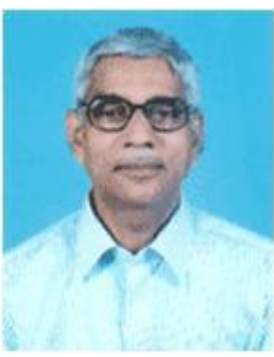

R. N. P. Choudhary (PhD: Edinburgh University) has actively been engaged in teaching and research for last 41 years at the institutes of national and international reputes such as IIT and NIT. He is one of the pioneer researchers and contributors in the field of ferroelectrics and related materials in India and abroad. He has guided more than $50 \mathrm{PhD}$ students and published more than 500 research papers in international/national journals. He is Fellow and member of a large number of national and international professional bodies/societies. He is an editorial board member of half a dozen of national/ international journals. Currently he is actively working on design and development of multifunctional materials.

\section{Introduction}

Nowadays, a large number of oxides of different structural families are available in different forms (ceramics, thin films and single crystals) for scientific and industrial applications. Some of them, such as $\mathrm{BaTiO}_{3}[1], \mathrm{PbZrTiO}_{3}$ [2], $\mathrm{ZnO}[3]$ etc are widely used for variety of electronic and other applications. Out of many non-linear devices, varistors are found voltage dependent, which has electrical behavior similar to that of back-to-back Zener diodes $[3,4]$. Because of non-linear I-V characteristic and energy absorption capability, $\mathrm{ZnO}$-based varistor modified with small amount of $\mathrm{Bi}_{2} \mathrm{O}_{3}, \quad \mathrm{Sb}_{2} \mathrm{O}_{3}, \quad \mathrm{Mn}_{3} \mathrm{O}_{4}, \quad \mathrm{Al}_{2} \mathrm{O}_{3}$, $\mathrm{Cr}_{2} \mathrm{O}_{3}$ etc.have extensively been studied [5-9]. Not much information on structural, capacitive and resistive behavior of a new composition of $\mathrm{ZnO}$ (with above oxides in equal ratio) is available. Therefore, we have attempted to synthesize and characterize $\mathrm{ZnSb}_{2} \mathrm{O}_{4}$. This material has extensively been studied in order to (i) enhance its electrical properties and (ii) to solve some inherent problems so that the material can be used as a non-linear device. In this paper we report some important features of dielectric and electrical properties. 


\section{Experimental}

\section{Materials}

Polycrystalline samples of $\mathrm{ZnSb}_{2} \mathrm{O}_{4}$ were prepared from pure oxides, $\mathrm{ZnO}(99.9 \%$, M/s. LobaChemie. Pvt. Ltd., India) and $\mathrm{Sb}_{2} \mathrm{O}_{3}(99.9 \%$, M/s. LobaChemie. Pvt. Ltd., India) in a suitable stoichiometry.

\section{Synthesis}

A conventional high-temperature solid-state reaction technique was used to synthesize the compounds. The ingredients were thoroughly mixed and ground in dry condition for $1 \mathrm{~h}$, and in wet atmosphere (methanol) for $1 \mathrm{~h}$ in an agate mortar and pestle to get homogenous mixture of the material. Then the mixed powders of the compound were calcined at $\sim 1150^{\circ} \mathrm{C}$ in alumina crucibles for $\sim 12 \mathrm{~h}$ in air atmosphere. The process of grinding and calcinations were repeated to ensure the formation of the compounds. The quality and formation of the compound was verified by an X-ray diffraction (XRD) technique. The fine and homogeneous powder of the above compound was pressed into cylindrical pellets of $10 \mathrm{~mm}$ diameter and 1-2 mm thickness under a uniaxial pressure of $5 \times 10^{6} \mathrm{~N} / \mathrm{m}^{2}$ using a hydraulic press. Polyvinyl alcohol (PVA) was used as a binder to reduce the brittleness of the pellets. The pellets were then sintered for $\sim 10 \mathrm{~h}$ at $\sim 1150^{\circ} \mathrm{C}$ in air atmosphere. The binder was burnt out during the sintering. Crystal structure and microstructure of the prepared compound was studied by an X-ray diffraction technique (XRD) and scanning electron microscopy (SEM) respectively. The sintered pellets were polished with fine emery paper and then coated with high-purity conducting silver paste. The pellets were dried at $150^{\circ} \mathrm{C}$ for about $4 \mathrm{~h}$.

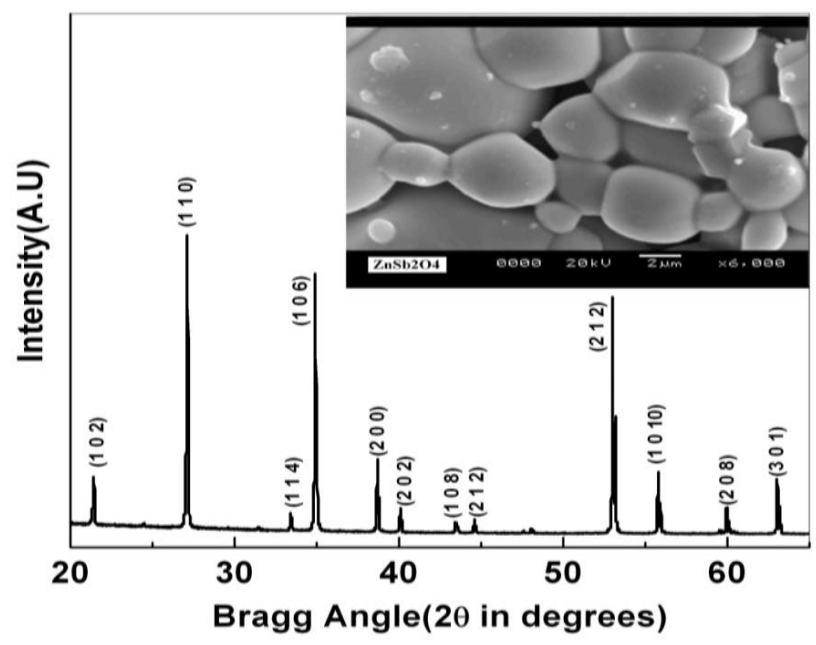

Fig. 1. X-ray diffraction pattern and (inset) SEM micrograph of $\mathrm{ZnSb}_{2} \mathrm{O}_{4}$ at room temperature.

\section{Characterization}

A preliminary structural analysis was carried out using Xray diffraction (XRD) technique by using an X-ray powder diffractometer (Rigaku Mini flex, Japan) in order to confirm the formation of single phase compound. The XRD pattern of the calcined powder was recorded at room temperature with $\mathrm{CuK}_{\alpha}(\lambda=1.5405 \AA)$ in a wide range of Bragg angles $2 \theta\left(20^{\circ} \leq 2 \theta \leq 65^{\circ}\right)$ at a scan rate of $3^{0}$ minute. The microstructure or texture of the pellet surface was recorded by a scanning electron microscope (SEM).

Electrical measurements were carried out on silveredcoated pellet samples. The capacitance in parallel mode $\left(\mathrm{C}_{\mathrm{p}}\right)$, dissipation factor $(\tan \delta)$, impedance $(\mathrm{Z})$ and phase angle $(\Phi)$ of $\mathrm{ZnSb}_{2} \mathrm{O}_{4}$ were obtained as a function of frequency $(1 \mathrm{kHz}-1 \mathrm{MHz})$ at different temperatures(30$\left.500^{\circ} \mathrm{C}\right)$ using a computer-controlled LCR/impedance meter (PSM 1735, N4L) with a laboratory-made furnace. A chromel-alumel thermo-couple and digital panel-voltmeter was used to measure the temperature. The $\mathrm{I} \sim \mathrm{V}$ characteristics were studied on the sintered-pellet of the compound, and the data were recorded using a computercontrolled sensitive electrometer (Keithley, model 6517B).

\section{Results and discussion}

\section{Structure/microstructure}

Fig. 1 shows sharp and single XRD peaks, which are different from that of ingredients, suggest the formation of a single-phase new compound [10]. A good agreement between observed and calculated interplanar spacing (d) was found in tetragonal crystal system at room temperature. The selected lattice parameters (a and c) of a tetragonal unit cell were refined using least-squares refinement sub-routine of POWD [11]. All of the diffraction peaks were indexed to those of the zinc antimoniate $\left(\mathrm{ZnSb}_{2} \mathrm{O}_{4}\right)$ with a spinel structure of lattice constants: $\mathrm{a}=4.6408 \AA, \mathrm{c}=18.6398 \AA$. The surface morphology of the pellet sample (Fig1 (inset)) shows small size grains homogenously-distributed throughout the surface of the sample.

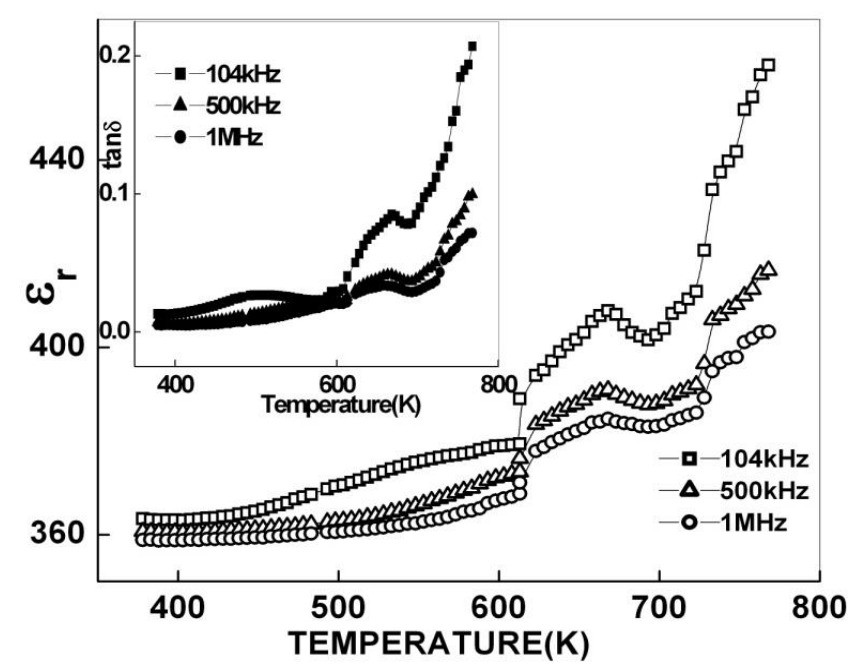

Fig. 2. Variation of $\varepsilon_{\mathrm{r}}$ and $\tan \delta$ with temperature at selected frequencies.

\section{Dielectric study}

The nature of variation of $\tan \delta$ with temperature follows the similar pattern as of $\varepsilon_{\mathrm{r}}$ as shown in Fig. 2. The dielectric anomaly is assumed to be related to the phase transition. The sharp increase in $\tan \delta$ at higher temperatures may be 
due to scattering of thermally activated charge carriers and some defects in the sample [12].

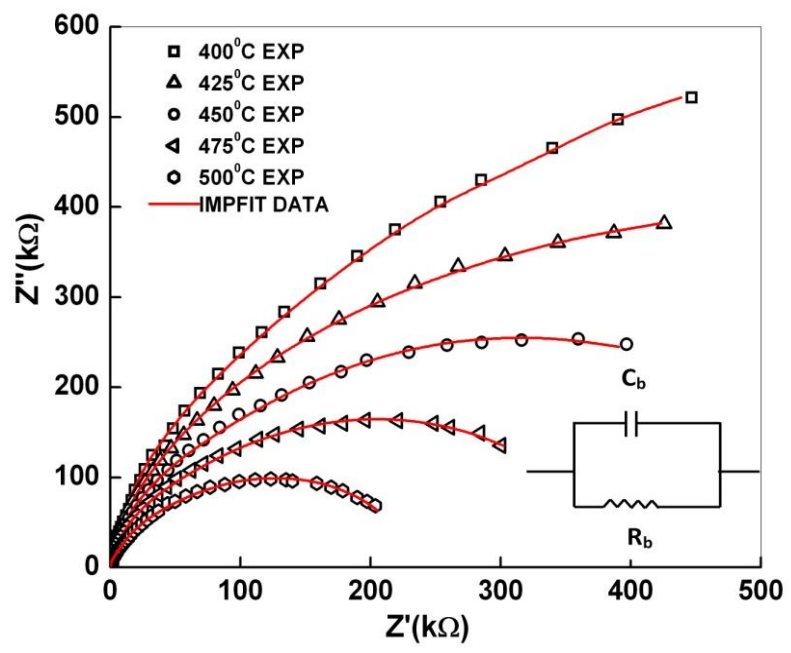

Fig. 3. Variation of Z' and Z' at selected temperatures (Impedance fitting).

Table 1. Comparison of dc conductivity, $\omega$ and $n$ at different temperatures.

\begin{tabular}{cccc}
\hline $\mathbf{T}\left({ }^{\circ} \mathbf{C}\right)$ & $\sigma_{\text {dc }}\left(\mathbf{o h m}^{-1} \mathbf{m}^{-1}\right)$ & $\boldsymbol{\omega}$ & $\mathbf{n}$ \\
\hline 400 & 0.00003 & $4.452 \mathrm{E}-7$ & 0.6116 \\
425 & 0.00004 & $2.0984 \mathrm{E}-7$ & 0.57209 \\
450 & 0.00005 & $4.452 \mathrm{E}-7$ & 0.53675 \\
475 & 0.00007 & $3.3219 \mathrm{E}-7$ & 0.59028 \\
500 & 0.00009 & $7.918 \mathrm{E}-6$ & 0.36968 \\
\hline
\end{tabular}

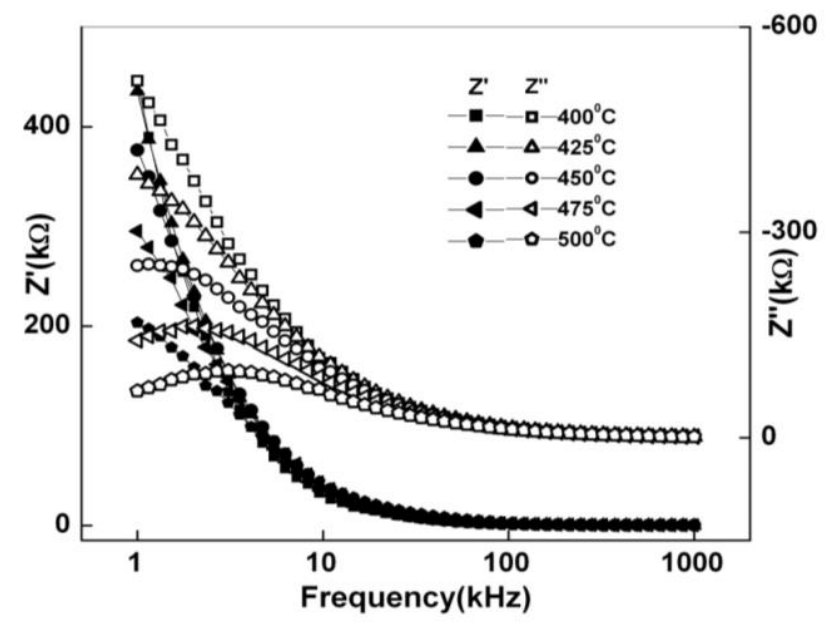

Fig. 4. Variation of $Z^{\prime} \& Z^{\prime \prime}$ with frequency at selected temperatures.

\section{Electrical properties: Complex impedance spectroscopy}

Complex impedance spectroscopy (CIS) was used to study the electrical properties of the compound. The frequency dependent properties of materials can be described via the complex dielectric permittivity $\left(\varepsilon^{*}\right)$, complex impedance $\left(\mathrm{Z}^{*}\right)$, complex admittance $\left(\mathrm{Y}^{*}\right)$, and dielectric loss $(\tan \delta)$. These parameters are related to each other by the following relations ; $Z^{*}=Z^{\prime}-j Z^{\prime \prime}=1 / j \omega C_{0} \varepsilon ; 1 / \varepsilon^{*}=j \omega C_{0} Z ; Y^{*}=Y^{\prime}+$ $j \mathrm{Y}^{\prime \prime}=j \omega \mathrm{C}_{0} \varepsilon^{*}$ and $\tan \delta=\varepsilon^{\prime \prime} / \varepsilon^{\prime}=\mathrm{Z}^{\prime} / \mathrm{Z}^{\prime \prime}=\mathrm{Y}^{\prime} / \mathrm{Y}^{\prime \prime}$, where $\omega=2 \pi f$ is the angular frequency, $\mathrm{C}_{0}$ is the geometrical capacitance, $j=\sqrt{ }-1)$. Fig. 3 shows the temperature dependence of complex impedance spectra (Nyquist plot) of the said compound over selected frequencies. The ZSIMP WIN version of software was used to analyze the data. In an ideal case (Debye-like response) an equivalent circuit has parallel combination of $\mathrm{CQR}$ and $\mathrm{CR}$ where $\mathrm{Q}$ is known as constant phase element (CPE), $\mathrm{R}$ is the resistance and $\mathrm{C}$ is the capacitance. Value of $n$ is between zero and one (for an ideal capacitor $n=1$ and for an ideal resistor $n=0$ ) [13].

Using the fitted curves, the values of bulk resistance $\left(\mathrm{R}_{\mathrm{b}}\right)$ and bulk capacitance $\left(\mathrm{C}_{\mathrm{b}}\right)$ at different temperatures were calculated and compared in Table $\mathbf{1}$. The decrease in the value of $R_{b}$ on increasing temperature indicates the existence of NTCR behavior in the material as generally observed in semiconductors [14]. No grain boundary and interfacial effect were observed. Depressed semi-circles indicate the presence of non-Debye type of relaxation [15, 16]. The intercept of each semi-circle on real $Z^{\prime}$-axis gives the contributions of bulk in the resistance/impedance. Fig. 4 shows the variation of real and imaginary parts of impedance (i.e., $Z^{\prime}$ and $Z^{\prime \prime}$ ) with frequency at different temperature. The value of $Z^{\prime}$ decreases with rise in temperature and frequency. It suggests reduction in bulk resistance. It is also observed that the value of $Z^{\prime}$ decreases till a certain fixed frequency up to $100 \mathrm{kHz}$, and attain a constant value above this frequency implying the possible release of space charge [17]. This indicates the absence of frequency relaxation process in the material [13].The decrease in $Z^{\prime \prime}{ }_{\text {max }}$ and the broadening of $Z^{\prime \prime}{ }_{\text {max }}$ peak with increase of temperature suggests the occurrence of temperature dependence of relaxation phenomenon in the material due to the presence of immobile charges at low temperatures and defects and vacancies at higher temperatures [18 - 20].

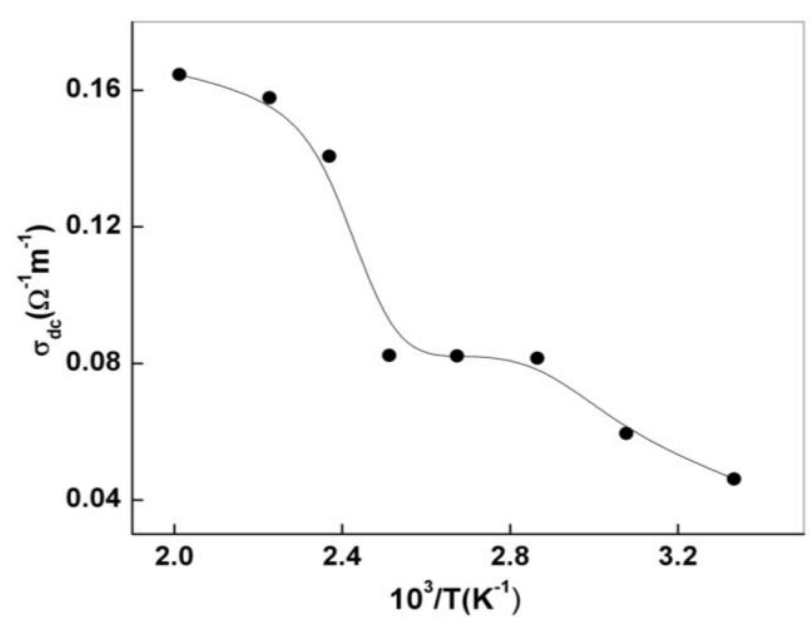

Fig. 5. Variation of dc conductivity with temperature.

\section{DC conductivity}

Fig. 5 shows the temperature dependence of dc conductivity of the material. It is observed that $\sigma_{\mathrm{d} c}$ increases with increase in temperature which supports the 
NTCR behavior of the sample. The nature of the plot follows the Arrhenius relation

$\sigma_{\mathrm{dc}}=\sigma_{0} \exp \left(-\mathrm{E}_{\mathrm{a}} / \mathrm{K}_{\mathrm{B}} \mathrm{T}\right)[19]$

The calculated activation energy $\left(E_{a}\right)$ of the sample in the temperature range of $27-76{ }^{\circ} \mathrm{C}$ is $0.24 \mathrm{eV}$, whereas it is $0.452 \mathrm{eV}$ in the temperature range of $125-176^{\circ} \mathrm{C}$. The variation of current density $(\mathrm{J})$ with applied dc electric field (E) at $30{ }^{0} \mathrm{C}$ and $150{ }^{\circ} \mathrm{C}$ is shown in Fig. 6.

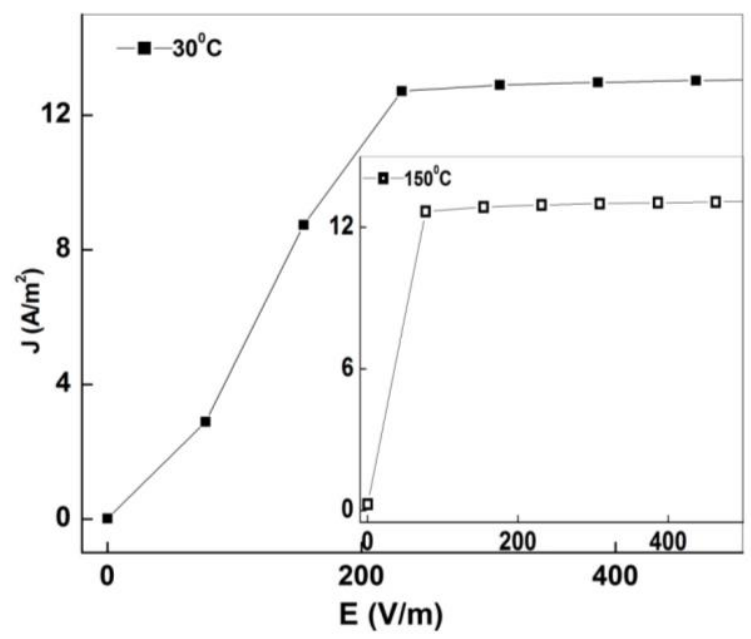

Fig. 6. Variation J with E selected temperatures.

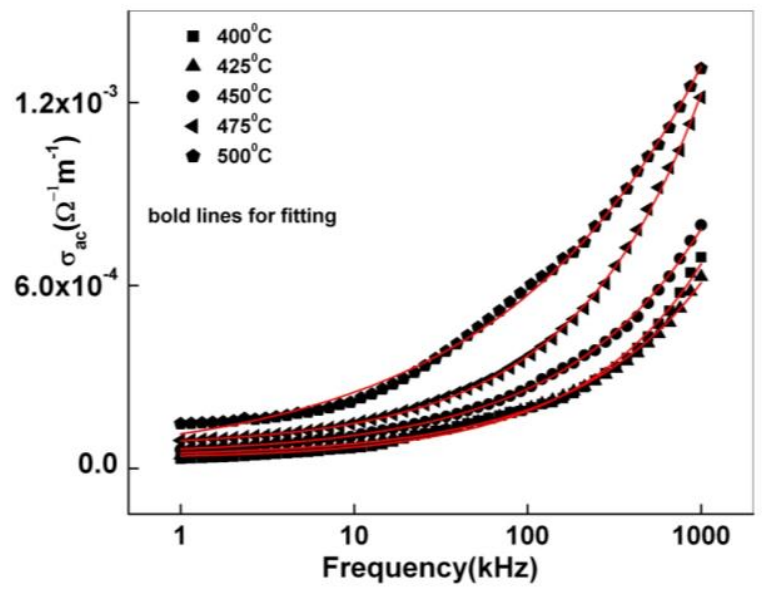

Fig. 7. Variation of ac conductivity with frequency.

\section{AC conductivity}

The ac electrical conductivity $\left(\sigma_{\mathrm{ac}}\right)$ was calculated using the dielectric data in an empirical relation: $\sigma_{\mathrm{ac}}=\omega \varepsilon_{\mathrm{r}} \varepsilon_{0} \tan \delta$, where $\varepsilon_{0}$ is permittivity in free space and $\omega$ is angular frequency. In order to have better understanding of conduction mechanism in the material, Jonscher's universal power law [21] is used:

$$
\sigma_{\mathrm{T}}(\omega)=\sigma(0)+\sigma_{1}(\omega)=\sigma_{0}+a \omega^{\mathrm{n}}
$$

where $\sigma(0)$ is the frequency independent term giving dc conductivity and $\sigma_{1}(\omega)$ is the purely dispersive component of ac conductivity having a characteristic of power law behavior in terms of frequency $(\omega)$. The exponent $n$ can have a value between zeros to one. Fig. 7 shows the variation of ac conductivity of the material as a function of frequency at different temperatures with non-linear fitting.

Table 2 Impedance-fitting data of $\mathrm{ZnSb}_{2} \mathrm{O}_{4}$.

\begin{tabular}{ccc}
\hline $\mathbf{T}\left({ }^{0} \mathbf{C}\right)$ & $\mathbf{R}_{\mathbf{b}}(\mathbf{k} \boldsymbol{\Omega})$ & $\mathbf{C}_{\mathbf{b}}(\mathbf{p F})$ \\
\hline $400^{\circ} \mathrm{C}$ & $1.858 \mathrm{E}+006$ & $9.847 \mathrm{E}-011$ \\
$425^{\circ} \mathrm{C}$ & $1.369 \mathrm{E}+006$ & $9.945 \mathrm{E}-011$ \\
$450^{\circ} \mathrm{C}$ & $7.751 \mathrm{E}+005$ & $9.799 \mathrm{E}-011$ \\
$475^{\circ} \mathrm{C}$ & $4.549 \mathrm{E}+005$ & $9.710 \mathrm{E}-011$ \\
$500^{\circ} \mathrm{C}$ & $2.828 \mathrm{E}+005$ & $8.640 \mathrm{E}-011$ \\
\hline
\end{tabular}

The conductivity plots reveal that the curves exhibit low frequency dispersion phenomena obeying the Jonscher's power law equation. According to Jonscher [19], the origin of the frequency dependence of conductivity lies in the relaxation phenomena arising due to mobile charge carriers. From the graphs it is obvious that $\sigma_{\mathrm{ac}}$ increases with rise in frequency but it is nearly independent at low frequency. The extrapolation of this part towards lower frequency side gives $\sigma_{\mathrm{dc}}$. In the high frequency region the curves approach each other. From non-linear fitting it is found that that motion of charge carriers is translational because of small value of $n(<1)$ [22]. The values of $\mathrm{dc}$ conductivity and $\mathrm{n}$ have been compared in Table 2 .

\section{Conclusion}

Finally, it is concluded that the titled compound $\mathrm{ZnSb}_{2} \mathrm{O}_{4}$ has tetragonal structure at room temperature. This compound shows dielectric anomaly. The contribution to the impedance comes from bulk only where the effect of grain boundary and interface is insignificant. This compound also exhibits negative temperature coefficient of resistance, which indicate the semi-conducting character of the material.

\section{Acknowledgements}

The authors are grateful to Dr. Maiti (CRF of IIT, Kharagpur), Dr. Dilip Mishra of IMMT, Bhubaneswar, Mr. R. Padhee and Samita Pattanaik of ITER for their help in experimental work and discussion.

\section{Reference}

1. Avrahami, Y. $\mathrm{BaTiO}_{3}$ based materials for Piezoelectric and Electrooptic applications.2003, 14

2. Shukla, A.; Choudhary, R. N. P. J. Mater Sci.2012, 47, 5074. DOI: $10.1007 / \mathrm{s} 10853-012-6308-3$

3. Alim, M.A.; Li, S.; Liu, F.; Cheng, P.Phys. Stat. Sol.2006, 203, 410427.

DOI: $10.1002 /$ pssa.200521084

4. Singh,P.; Ashvani, K.; Kaushal, A.; Kaur, D.; Pandey, A.; Goyal, R. N.Bull. Mater. Sci .2008, pp. 573-577. (C) Indian Academy of Sciences.

DOI: $10.1007 / \mathrm{s} 12034-008-0089-\mathrm{y}$

5. Aref, S.M.; Bidadi, H.; and Hasanli, S. Int. J. Polymer Sci.2010, (Article ID 241430, 5 pages) DOI: $\underline{10.1155 / 2010 / 241430}$

6. Ferna' ndez-Heviaa, D.; Peiteadob, M.; Frutosa, J. de. Caballerob A.C.; Ferna' ndezb, J.F., J. Euro. Ceram. Soc. 2004, 24, 1205. DOI: $\underline{10.1016 / \mathrm{S} 0955-2219(03) 00411-4}$

7. Hong,Y.W.;Kim, J.H. Ceram. International. 2003, 30(7), 1301 
DOI: $10.1016 /$ i.ceramint.2003.12.028

8. Arefin, M.L.; Raether, F.; Dolejs, International.2009, 35, 3313.

DOI: $10.1016 /$ j.ceramint.2009.05.030

9. Metz, R.; Delalu, H.; Vignalou, J.R.; Achard, N.;Elkhatib, M. Mater. Chem. Phys. 2000, 63,157.

DOI: $10.1016 / \mathrm{S} 0254-0584(99) 00227-8$

10. Klug, H.P.; Alexander, L.E. X-Ray Diffraction Procedures. For Polycrystalline andAmorphous Materials, Wiley, Chester (England), 1974, 966.

11. E.W. POWD, An Interactive Powder Diffraction Data Interpretation and Indexing Program, Version 2.1, School of Physical Science, Flinders University of South Australia, Bedford Park, SA 5042, Australia.

12. Ganguli, P.; Devi, S.; Jha, A.K.; Deori ,K.L. Ferroelectrics. 2009, 381, 111 DOI: $10.1080 / 00150190902869772$

13. Macdonald, J.R., Solid St. Ionics.1984, 13, 147. DOI: $10.1016 / 0167-2738(84) 90049-3$

14. RajivRanjan; Rajiv, Kumar; Nawnit, Kumar; Behera, B.; Choudhury, R.N.P. J.Alloys. Compd.2011,509, 6388. DOI: $10.1016 /$ j.jallcom.2011.03.003

15. Sen. S.; Choudhary, R.N.P.; Pramanik, P.Physica B. 2007, 387, 56. DOI: $10.1016 /$ i.physb.2006.03.028

16. Behera, B.;Nayak, P;Choudhary R.N.P., J. Alloys Compd. 2007, 436, 226.

DOI: $\underline{10.1016 / j . j a l l c o m .2006 .07 .028}$

17. Plocharski, J; Wieczoreck, W. Solid State Ionics.1982,28, 979. DOI: $10.1016 / 0167-2738(88) 90315-3$

18. Sahoo, S.; Pradhan, D.K.; Choudhary R. N. P.; Mathur,B. K. Adv. Mat. Lett. 2012,3(2), 97.

DOI: $10.5185 /$ amlett.2011.4250

19. Jonscher ,A.K.Nature.1977,267, 673. DOI: $\underline{10.1038 / 267673 \mathrm{a} 0}$

20. Suman,C. K.; Prasad, K.;Choudhary, R. N. P. J. Mat. Sci.2006,41, 369

DOI: $10.1007 / \mathrm{s} 10853-005-2620-5.28$

21. Sinclair, D. C.; West, A. R., J. Appl. Phys. 1989,66, 3850

DOI: $10.1063 / 1.344049$

22. Funke, K. Prog. Solid State Chem. 1993, 22, 111.

DOI: $\underline{10.1016 / 0079-6786(93) 90002-9}$

\section{Advanced Materials Letters}

\section{Publish your article in this journal}

ADVANCED MATERIALS Letters is an international journal published quarterly. The journal is intended to provide top-quality peer-reviewed research papers in the fascinating field of materials science particularly in the area of structure, synthesis and processing, characterization, advanced-state properties, and applications of materials. All articles are indexed on various databases including $\mathrm{DOAJ}$ and are available for download for free. The manuscript management system is completely electronic and has fast and fair peer-review process. The journal includes review articles, research articles, notes, letter to editor and short communications. 